\title{
A STUDY ON VARIATIONS OF NUTRIENT FORAMEN OF ULNA IN SAURASHTRA REGION WITH ITS CLINICAL RELEVANCE
}

\author{
Sanjay R Chavda ${ }^{1}$, Aashish J Rathwa ${ }^{* 2}$, Vraj Akbari ${ }^{3}$. \\ ${ }^{1}$ Assistant Professor, Department of Anatomy, P.D.U. Medical College, Rajkot, Gujarat, India. \\ ${ }^{*}$ Tutor, Department of Anatomy, P.D.U. Medical College, Rajkot, Gujarat, India. \\ ${ }^{3}$ Assistant Professor, PDU Govt. Medical College, Rajkot, Gujarat, India.
}

\section{ABSTRACT}

Background: Nutrient foramen is an opening into shaft of Ulna which gives passage to the blood vessels of medullary cavity. The knowledge of nutrient foramen is important in surgical procedures like bone grafting and more recently in microsurgical vascularized bone transplantation.

Objective: To determine the number, location and direction of nutrient foramen and whether the nutrient foramens obey the rule of ossification, that is directed away from the growing end of the bone or not.

Method: The present study consisted of 150 (75 right and 75 left) dried ulna bones excluding any fracture or pathological abnormalities Number and direction of nutrient foramen was observed in each ulna. Location of nutrient foramen in relation with surfaces and zones of ulna was determined.

Result: It has been observed that $96.67 \%$ of the ulna had a single nutrient foramen, $1.33 \%$ double foramen and $2 \%$ had no nutrient foramen. It was concluded that $90 \%$ of the nutrient foramina were present on the anterior surface, $5.33 \%$ on anterior border and $4.67 \%$ on interosseous border It was also concluded that most (62.67\%) of the foramina present in the zone II followed by zone I (23.33\%) then by zone III (14\%). All foramina were directed toward the upper end of ulna.

Conclusion: By knowing the number and location of the nutrient foramina in ulna would be useful in preventing intra-operative injury of nutrient artery during orthopedic, plastic and reconstructive surgery and will also be relevant in medico legal practice.

KEY WORDS: Clinical Implications, Foraminal Index, Ulna, Nutrient Foramen.

Address for Correspondence: Dr. Aashish J Rathwa, Tutor, Department of Anatomy, P.D.U. Medical College, Rajkot - 360001, Gujarat, India. Mobile No: 8758898589

E-Mail: aashish.rathwa60@gmail.com

Access this Article online

Quick Response code

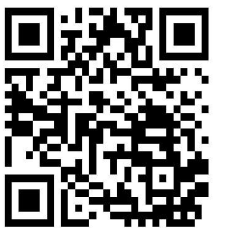

DOI: $10.16965 /$ ijar.2018.358

Journal Information

International Journal of Anatomy and Research

ICV for 2016 ISSN (E) 2321-4287 | ISSN (P) 2321-8967

90.30 https://www.ijmhr.org/ijar.htm

DOI-Prefix: https://dx.doi.org/10.16965/ijar

Article Information

Received: 13 Aug 2018

Peer Review: 13 Aug 2018

Revised: None
Accepted: 03 Oct 2018

Published (O): 05 Nov 2018

Published (P): 05 Nov 2018

\section{INTRODUCTION}

Nutrient foramen is an opening into the shaft of ulna bone. It leads to oblique nutrient canal passing through cortex and ultimately opens into the medullary cavity. The nutrient artery enters into the medullary cavity through nutrient foramen and the canal which is a rich source of blood supply to the medullary cavity and inner two-third of cortex of the ulna [1].
The nutrient blood supply is crucial for any long bones and it should be preserved in order to promote the fracture healing [2]. Moreover, the presence of preserved nutrient blood supply is essential for the survival of the osteocytes in cases of tumor resection, trauma, and congenital pseudoarthrosis [3].

It is usually single in number and located on the antero-medial surface of the ulna a little below 
its midpoint close to the interosseous border. It is usually directed toward the upper end of ulna [4]. The number and location of foramina remains are non-constant feature in long bones [5]. Henderson RG also reported that their location in mammalian bones are variable and may alter during the growth [6]. Knowledge of the number and location of nutrient foramina is useful in certain surgical procedures [7].

Studies on the vascularization of long bones of various populations were conducted analyzing the nutrient foramina morphometry and the vascular anatomy in reconstructive surgeries [8-11].

Therefore, the aim of this study was to study the precise anatomy of nutrient foramina in adult human ulna of saurashtra region. This knowledge was of tremendous significance to orthopedic surgeons performing procedures involving bone grafts, fracture repair, joint replacement and vascularized bone microsurgery.

\section{MATERIALS AND METHODS}

Study was conducted in the Department of Anatomy, P.D.U. Medical College Rajkot, Gujarat, India and GMERS medical college, Junagarh, Gujarat, India. Total 150 adult human cleaned and dried ulna bones were included in the study. All selected bones were normal with no appearance of pathological changes. The specific age and sex characteristics of the bones studied were unknown. The nutrient foramina were observed in all bones with the help of a hand lens. They were identified by the elevated margins and by the presence of a distinct groove proximal to them. Only well-defined foramina on the diaphysis were accepted for present study. Foramina at the ends of the bones were ignored. Foramina smaller than a size 24 hypodermic needle were considered secondary and these were not analyzed or reported in this study. The position of all nutrient foramina was determined by calculating the foraminal index (FI) using the formula: $\mathrm{FI}=(\mathrm{DNF} / \mathrm{TL}) \times 100$ where DNF is the distance from the proximal end of the bone to the nutrient foramen; TL is total bone length (Fig 3). The position of the foramina was divided into three types according to $\mathrm{Fl}$ as mentioned below. Type - 1: Fl below 33.33, the foramen was in the proximal third of the bone. Type - 2: Fl from 33.33 up to 66.66 , the foramen was in the middle third of the bone. Type - 3: $\mathrm{FI}$ above 66.66, the foramen was in the distal third of the bone. All measurements were taken to the nearest $0.1 \mathrm{~mm}$ using vernier caliper 2 . The observations and measurements were presented in descriptive statistics.

\section{RESULTS}

The following observations were found to conclude the results of the study.

Number of foramina: As shown in Table 1, the single nutrient foramen was present in $60.19 \%$ (97.33) of right ulna and $96 \%$ (72) of left ulna, double nutrient foramina in no(0) right ulna and $2.67 \%$ (2) of left ulna The nutrient foramina were found to be absent in $2.67 \%$ (2) of right ulna and $1.33 \%$ (1) of left ulna.

It has been concluded that $96.67 \%$ of the ulna had a single nutrient foramen. The double foramen was observed in $1.33 \%$ of the ulna (Fig 1). $2 \%$ of ulna did not have any nutrient foramina.

Table 1: Number of nutrient foramen of ulna.

\begin{tabular}{|c|c|c|c|c|c|c|}
\hline $\begin{array}{c}\text { No of nutrient } \\
\text { foramen }\end{array}$ & \multicolumn{2}{|c|}{ Right } & \multicolumn{2}{c|}{ Left } & \multicolumn{2}{c|}{ Total } \\
\hline & No of ulna & $\%$ & No of ulna & $\%$ & No of ulna & $\%$ \\
\hline 0 & 2 & 2.67 & 1 & 1.33 & 3 & 2 \\
\hline 1 & 73 & 97.33 & 72 & 96 & 145 & 96.67 \\
\hline 2 & 0 & 0 & 2 & 2.67 & 2 & 1.33 \\
\hline Total & 75 & 100 & 75 & 100 & 150 & 100 \\
\hline
\end{tabular}

Location of foramina: It has been observed that a total of 149 numbers of nutrient foramina were found to be present in all studied ulna. In relation to surfaces, it was found that anterior surface had $89.04 \%$ (65) of nutrient foramina in right ulna and $90.79 \%$ (69) of nutrient foramina in left ulna, anterior border had $5.48 \%(04)$ of nutrient foramina in right ulna and 5.26\% (04) of nutrient foramina in left ulna and interosseous border had $5.48 \%(04)$ of nutrient foramina in the right ulna and $3.95 \%(03)$ of nutrient foramina in the left ulna were found as shown in Table 2.

Therefore, it was concluded that the majority $89.93 \%$ of the nutrient foramina were found to be present on the anterior surface of the shaft of ulna, followed by $5.37 \%$ of the nutrient foramina were concentrated on the anterior border and $4.70 \%$ of the nutrient foramina were located on the interosseous border of the shaft of ulna. 

ITS CLINICAL RELEVANCE.

As shown in Table 3, the incidence of nutrient foramina present in Zone I of the shaft of ulna was found to be $24.66 \%$ (18) in right ulna and $19.73 \%(15)$ in left ulna. It was observed that 44 nutrient foramina (60.27\%) were present in Zone II of right ulna and 51 nutrient foramina (67.11\%) in Zone II of left ulna. It was also observed that 11 nutrient foramina (15.07\%) were present in Zone III of right ulna and 10 nutrient foramina (13.16\%) in Zone III of left ulna in relation to the zones.

Table 2: Location of nutrient foramen of ulna.

\begin{tabular}{|c|c|c|c|c|c|c|}
\hline Location & \multicolumn{2}{|c|}{ Right ulna } & \multicolumn{2}{c|}{ Left ulna } & \multicolumn{2}{c|}{ Total ulna } \\
\hline & No of ulna & $\%$ & No of ulna & $\%$ & No of ulna & $\%$ \\
\hline Anterior border & 4 & 5.48 & 4 & 5.26 & 8 & 5.37 \\
\hline Interosseous border & 4 & 5.48 & 3 & 3.95 & 7 & 4.7 \\
\hline Anterior surface & 65 & 89.04 & 69 & 90.79 & 134 & 89.93 \\
\hline Total & 73 & 100 & 76 & 100 & 149 & 100 \\
\hline
\end{tabular}

Overall incidence of presence of nutrient foramina in the middle one-third or Zone II of the shaft of ulna were $63.76 \%$, followed by the upper one-third or Zone I (22.15\%) and by lower one-third or zone III (14.09\%).

Table 3: Showing distribution of nutrient foramen in respect to zone of ulna.

\begin{tabular}{|c|c|c|c|c|c|c|}
\hline Zone & \multicolumn{2}{|c|}{ Right (73) } & \multicolumn{2}{c|}{ Left (76) } & \multicolumn{2}{c|}{ Total149 } \\
\hline & Number & $\%$ & Number & $\%$ & Number & $\%$ \\
\hline Zone I & 18 & 24.66 & 15 & 19.73 & 33 & 22.15 \\
\hline Zone II & 44 & 60.27 & 51 & 67.11 & 95 & 63.76 \\
\hline zone III & 11 & 15.07 & 10 & 13.16 & 21 & 14.09 \\
\hline Total & 73 & 100 & 76 & 100 & 149 & 100 \\
\hline
\end{tabular}

Direction of foramina: The direction of nutrient foramina was not showing any deviation from normal anatomical feature even in single case throughout the study. All the foramina were directed upwards or toward the upper end of ulna as shown in Fig 1

As shown in Table 4, the mean total length of ulna was found to be $24.05 \mathrm{~cm}$ in right and 24.91 $\mathrm{cm}$ in left ulna; and mean distance from proximal end of ulna to the nutrient foramen was found to be $9.30 \mathrm{~cm}$ for right and $8.89 \mathrm{~cm}$ for left ulna and the foraminal index was found to be $36.20 \%$ on right ulna and $34.47 \%$ on left ulna. Therefore, an average the total mean length of ulna was found to be $24.48 \mathrm{~cm}$; and mean distance from proximal end of ulna to the nutrient foramen was found to be $9.10 \mathrm{~cm}$ and the mean foraminal index was found to be $35.34 \%$.
Table 4: Showing mean values of statistical measurements of ulna.

\begin{tabular}{|c|c|c|c|}
\hline Parametre & Right 75 & Left 75 & Total 150 \\
\hline Mean total length & $24.05 \mathrm{~cm}$ & $24.91 \mathrm{~cm}$ & $24.48 \mathrm{~cm}$ \\
\hline $\begin{array}{c}\text { Distance from proximal } \\
\text { end to NF }\end{array}$ & $9.30 \mathrm{~cm}$ & $8.89 \mathrm{~cm}$ & $9.10 \mathrm{~cm}$ \\
\hline Foraminal Index & $36.20 \%$ & $34.47 \%$ & $35.34 \%$ \\
\hline
\end{tabular}

Fig. 1: Nutrient foramen in ulna

Fig. 2: Measuring from proximal end
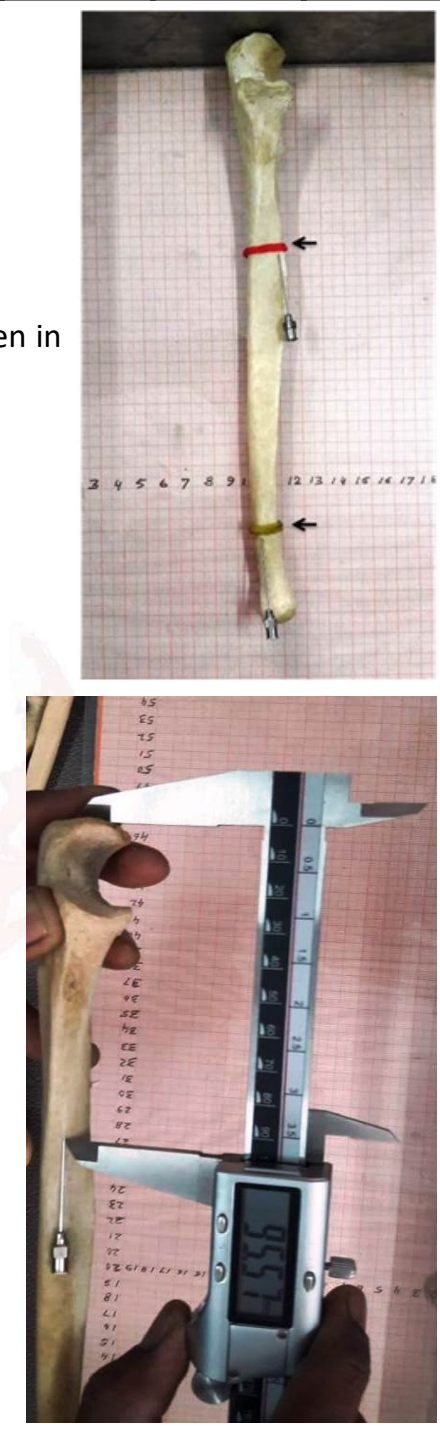

Fig. 3: Total length of ulna.

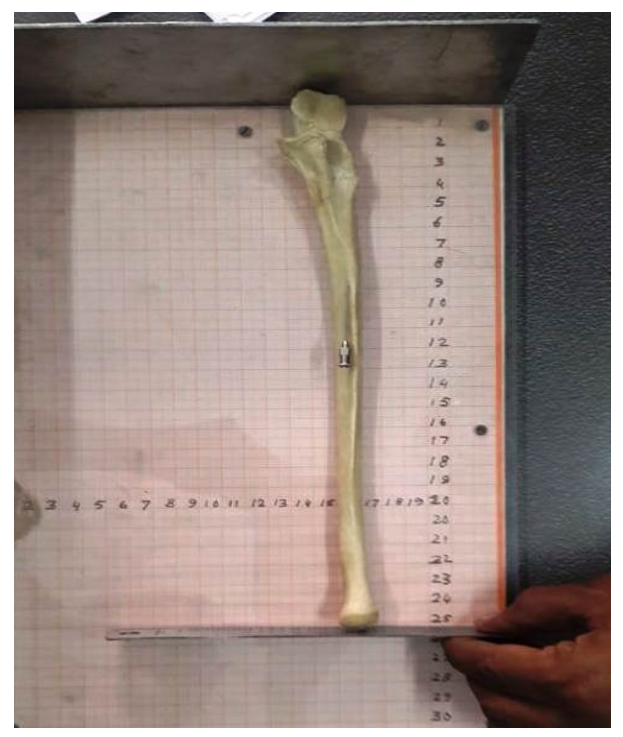




\section{DISCUSSION}

Number of nutrient foramina: In the present study, a single nutrient foramen had a higher percentage $(96.67 \%)$ in the ulna bones, compared to that of double (1.33\%), and no nutrient foramen (2\%). Many studies reported a percentage approximately similar to that of our study by Kizilkanat E [13] and by Kumar S [14]. The range of occurrence of double foramina varied from $13 \%$ by Kirschner $\mathrm{MH}$ [15], $26 \%$ by Kumar S [14], and 42\% by Mysorekar VR [7]. Also, some reported the absence of nutrient foramina in some bones by Joshi $H$ [12] and by Kizilkanat $E$ [13]; which is in accordance to the present study as $2 \%$ of ulna observed was without nutrient foramen.

Direction of nutrient foramina: In present study, most of the nutrient foramina in ulna were directed proximally (away from the growing ends) which was similar to the study by Kumar, et al. [14].

Position of nutrient foramina: In our study, most of nutrient foramina were located along the middle third of the ulna followed by upper third and then lower third, which were correlated with other studies by Kizilkanat E [13]and by Nagel A.[ 8]. Similar findings had been reported by Kizilkanat, et al. [13], and Kumar, et al. [14].

Clinical relevance: Position and number of the nutrient foramina in long bones is very important in orthopedic surgical procedures like joint replacement therapy, fracture repair, bone grafts and vascularized bone microsurgery [13]. Injury to the nutrient artery at the time of fracture, or at subsequent manipulation, may be a significant factor predisposing to faulty union. The levels of osseous section are selected according to the localization of the diaphyseal nutrient foramina in order to preserve diaphyseal vascularization of the recipient to support the consolidation with the osseous graft [16].

\section{Conflicts of Interests: None}

\section{REFERENCES}

[1]. Krishna Garg. BD Chaurasia's Hand Book of General Anatomy. Blood supply of bones. 4th ed. 2011. CBS Publishers and Distributors Pvt. Ltd:43-44.

[2]. Longia GS, Ajmani ML, Saxena SK, Thomas RJ. Study of diaphyseal nutrient foramina in human long bones. Acta Anat. 1980;107:399- 406.
[3]. Sendemir E, Cimen A. Nutrient foramina in the shafts of lower limb long bones: situation and number. Surg Radiol Anat. 1991; 13:105-8.

[4]. Standring S. Gray's Anatomy, 40th ed. CHURCHILL LIVINGSTONE ELSEVER, 2008:798.

[5]. Bokariya P, Gudadhe D, Kothari R, Murkey PN, Shende MR. Comparison of humerus and femur with respect to location and number of nutrient foramina. Indian Journal of Forensic Medicine and Pathology. 2012;5(2):79-81.

[6]. Henderson RG. The position of the nutrient foramen in the growing tibia and femur of the rat. J Anat. 1978; 125(3):593-9.

[7]. Mysorekar VR. Diaphysial nutrient foramina in human long bones. J Anat. 1967;101(4):813-22.

[8]. Nagel A. The clinical significance of the nutrient artery. Orthop Rev 1993;22:557-61.

[9]. Dyankova S. Vascular anatomy of the radius and ulna diaphyses in their reconstructive surgery. Acta Chir Plast 2004; 46:105-9.

[10]. Choi SW, Kim HJ, Koh KS, Chung IH, Cha IH. Topographical anatomy of the fibula and peroneal artery in Koreans. Int J Oral Maxillofac Surg 2001;30:329-32.

[11]. Schiessel A, Zweymuller K. The nutrient artery canal of the femur: a radiological study in patients with primary total hip replacement. Skeletal Radiol 2004;33:142-9

[12]. Joshi H, Doshi B, Malukar O. A study of the nutrient foramina of the humeral diaphysis. NJIRM 2011;2:14-17.

[13]. Kizilkanat E, Boyan N, Ozsahin ET, Soames R, Oguz $O$. Location, number and clinical significance of nutrient foramina in human long bones. Ann Anat. 2007;189:87-95.

[14]. Kumar S, Kathiresan K, Gowda MST, Nagalaxmi. Study of diaphyseal nutrient foramina in human long bones. Anat Karnataka.2012;6(2): 66-70.

[15]. Kirschner MH, Menck J, Hennerbichler A, Gaber O, Hofmann GO. Importance of arterial blood supply to the femur and tibia transplantation of vascularized femoral diaphiseal and knee joints. World J. Surg., 1998; 22: 845-52.

[16]. Wavreille G., Remedios, Dos C., Chantelot C. Anatomic bases of vascularized elbow joint harvesting to achieve vascularised allograft. Surg. Radiol. Anat., 2006;28:498-510.

How to cite this article: Sanjay R Chavda, Aashish J Rathwa, Vraj Akbari. A STUDY ON VARIATIONS OF NUTRIENT FORAMEN OF ULNA IN SAURASHTRA REGION WITH ITS CLINICAL RELEVANCE. Int J Anat Res 2018;6(4.2):5844-5847. DOI: 10.16965/ijar.2018.358 